\title{
Operational Risk and Reputation in Financial Institutions: Does Media Tone Make a Difference?
}

\author{
Ahmed Barakat*,a, Simon Ashby ${ }^{\mathrm{b}}$, Paul Fenn ${ }^{\mathrm{a}}$, Cormac Bryce
}

\begin{abstract}
Operational risk announcements are unexpected adverse media news that potentially harm the reputation of financial institutions. This paper examines the equity-based and debt-based reputational effects of financial sentiment tones in operational risk announcements and shows how such reputational effects are moderated by alternative sources of public information. Our analysis reveals that the net negative tone and litigious tone have adverse reputational effects, and the uncertainty tone mitigates the adverse reputational impact. Additionally, alternative, simultaneous sources of information neutralize the reputational effects of textual tones. First, third-party information about the event (i.e. regulatory announcements and final settlements) dissolves the favorable (adverse) reputational impact of the uncertainty tone (litigious tone). Second, loss amount disclosure and firm recognition substitute the reputational effects of the net negative tone and uncertainty tone only in Anglo-Saxon countries and market-based economies. Overall, our findings indicate that the reputational effects of the media materialize most when there is lack of certain, quantifiable and regulated public information about the operational risk event.
\end{abstract}

Keywords: Content Analysis, Financial Sentiment, Media News, Operational Risk, Reputational Risk, Textual Tone

JEL Classifications: D8 Information, Knowledge, and Uncertainty, G1 General Financial Markets, G2 Financial Institutions and Services

* Corresponding author: Finance, Risk and Banking Division, Nottingham University Business School, Jubilee Campus, Nottingham, NG8 1BB, United Kingdom. Email: ahmed.barakat@nottingham.ac.uk. Tel: $+44(0) 1158466643$.

a) Finance, Risk and Banking Division, Nottingham University Business School, University of Nottingham.

b) Plymouth Business School, Faculty of Business, Plymouth University.

c) City, University of London, Cass Business School, Faculty of Actuarial Science and Insurance. 


\section{Acknowledgements}

The authors are grateful to ORIC International for providing us with access to their proprietary operational risk announcement database, and their institutional members in order to consider the applicability of our findings. We would also like to thank the University of Nottingham for 'SPARK' financial support. Earlier drafts of this paper have benefited from helpful comments received from delegates at the European Risk Research Network (ERRN) Conference where it won 'Best Conference Paper' held at the University of York, United Kingdom in September 2016, the International Finance and Banking Society (IFABS) Conference held at the University of Oxford, United Kingdom in July 2017, and the Operational Risk Research Conference held at the Federal Reserve Bank of Richmond, Charlotte, United States of America in July 2018. 